\title{
BIODIVERSITAS DAN POPULASI IKAN KARANG DI PERAIRAN SELAT SEMPU SENDANG BIRU KABUPATEN MALANG JAWA TIMUR
}

\author{
REEF FISH BIODIVERSITY AND POPULATION IN SEMPU STRAIT WATERS SENDANG BIRU \\ MALANG REGENCY EAST JAVA
}

\author{
Oktiyas Muzaky Luthfi ${ }^{\star}$, Putri Pujarahayu, Kirana Fajar S, Ahmad Wahyudiarto, Saifur Rizal \\ Fakri, Muhammad Sofyan, Faruk Ramadhan, M. Abdul Ghofur A, Syakanov Murian, Irham \\ Tovani, Mahmud, Danang Adi, Firdaus Abdi \\ Program Studi IImu Kelautan, Fakultas Perikanan dan IImu Kelautan \\ Universitas Brawijaya Malang \\ *Corresponding author e-mail: omuzakyl@ub.ac.id \\ Received: January 25, 2016/Accepted: March 30, 2016
}

\begin{abstract}
Reef fish is one of the conspicuous inhabitant in the reef ecosystem. Damage to coral reefs in many countries due to human factors (anthropogenic) and naturally has an impact on the abundance of different species of reef fish. Over fishing is one of the causes of death of reef fish are widely reported. The nature reserve of Sempu Island also became conservation areas for reef fish. Monitoring of reef fish actually can determine on condition of coral reefs, fisheries potential and suitability of ecosystem based on the number of fish that live in the surrounding reef. Observations were made at $3 \mathrm{~m}$ depth in the Sempu strait. We used the Reef Check line intercept transect along 100 meters in two research stations. Result showed that 5 families of reef fishes was found, there were Chaetodontidae, Haemulidae, Lutjanidae, Scaridae and Muraenidae. Diversity Index ( $H$ ') reef fish in Teluk Semut was 0.215, and dominance index (C) was 0.083. Observations showed that coral reef conditions have correlation to the distribution of reef fish, and the presence of reef fishes can be used as bio indicator of the coral reef damage.
\end{abstract}

Keywords: coral reef, nature reserve, reef check, reef fishes, Sempu Island.

\section{ABSTRAK}

Ikan karang adalah salah satu penyusun ekosistem utama di terumbu. Kerusakan terumbu karang di berbagai negara diakibatkan faktor manusia (anthropogenic) dan alamiah telah berdampak pada kelimpahan berbagai jenis ikan karang. Over fishing adalah salah satu penyebab kematian ikan karang yang banyak dilaporkan. Pulau Sempu yang berstatus cagar alam menjadi kawasan konservasi bagi ikan karang. Pengamatan ikan karang dilakukan untuk mengetahui kondisi terumbu karang, potensi perikanan dan kesesuaian ekosistem berdasarkan jumlah ikan karang yang hidup di sekitarnya. Pengamatan dilakukan pada kedalaman 3 meter di Selat Sempu Kabupaten Malang Jawa Timur. Metode yang digunakan dalam penelitian ini adalah metode Reef Check menggunakan Line Intercept Transect sepanjang 100 meter. Ikan yang ditemukan adalah dari family Chaetodontidae, Haemulidae, Lutjanidae, Scaridae dan Muraenidae. Indeks Keanekaragaman (H') ikan karang di Teluk Semut sebesar 0.215, Indeks Dominansi (C) yaitu sebesar 0.083. Hasil pengamatan menunjukan adanya hubungan antara kondisi terumbu karang dan potensi perairan dengan keberadaan ikan karang.

Kata kunci: cagar alam, ikan karang, Pulau Sempu, reef check, terumbu karang.

\section{PENDAHULUAN}

Selat Sempu merupakan selat yang berada pada Pantai Sendang Biru Desa Sitiarjo dan berjarak $70 \mathrm{~km}$ dari pusat Kota Malang. Selat Sempu terletak berdekatan dengan Dusun Sendang Biru dan berhubungan langsung dengan Samudera Hindia. Banyak kegiatan perikanan tangkap 
dilakukan di selat ini, sehingga dikatakan daerah ini sebagai penyangga perekonomian masyarakat sekitarnya.

Ikan karang merupakan salah satu penyusun ekosistem utama di terumbu karang, hampir seluruh hidup dari ikan karang akan sangat tergantung secara langsung maupun tidak langsung dengan keberadan terumbu karang. Ikan karang seperti kakap (snapper/Lutjanus), betok (damselfish/Pomacentridae), dan beronang (rabbitfish/Siganus) ketika masa juvenile akan berada dikawasan dangkal seperti mangrove dan lamun, namun ketika dewasa mereka akan bermigrasi kedaerah terumbu karang. Nilai ekonomis ikan karang di Indonesia diperkirakan lebih dari 15.340 US dolar per $\mathrm{km}^{2}$ (Pet-Soede et al., 1999). Namun meningkatnya kegiatan penangkapan ikan (over fishing), aktifitas perusakan terumbu karang, pemboman, dan pariwisata akan mengurangi tutupan karang hidup pada suatu wilayah, sehingga terjadinya pergantian (phase shift) dari wilayah yang didominasi karang menjadi wilayah yang didominasi oleh alga, dan akan berdampak secara signifikan terhadap jumlah dan populasi ikan (Cole et al., 2009). Dominansi ikan karang akan digantikan dengan dominansi ikan pemakan alga (Wilkinson, 1999). Salah satu tanda dari sudah terjadinya penurunan jumlah ikan karang akibat overfishing dan kerusakan terumbu karang adalah adanya penurunan jumlah tangkapan ikan dan ukuran ikan yang ditangkap semakin kecil (Jackson et al., 2001). Monitoring ikan karang pada secara rutin dan menggunakan metode sederhana dan akurat harus selalu dilakukan, sehingga nanti akan didapatkan base line data ikan karang yang meliputi distribusi, kelimpahan dan keanekaragamannya. Joyce et al. (2004) menyatakan banyak cara yang telah dilakukan para ahli untuk melakukan monitoring ikan karang, seperti menggunakan pendekatan remote sensing, acoustic beam, video dan pengamatan visual langsung.

Metode secara visual di dalam laut merupakan salah satu cara untuk mengestimasi kerapatan dan keberagaman ikan di sekitar karang (Halford and Thompson, 1994). Metode ini dilakukan untuk melihat kondisi ekosistem terumbu karang dan ekosistem di sekitarnya akibat perubahan iklim yang terus terjadi, disamping itu juga berguna untuk indikator keberhasilan saat akan membuat kawasan marine protected area (MPA). Pengamatan secara visual yang dilakukan di laut disamping memiliki kelebihan karena dapat dilakukan dengan cepat, juga memiliki kekurangan yaitu adanya bias penghitungan dimana pengamat tidak bisa membedakan ikan yang sudah dihitung dengan yang belum. Disamping itu, terkadang kondisi perairan yang kurang jernih akan mempengaruhi penghitungan dan estimasi ukuran ikan (Dearden et al., 2010). Tujuan dari penelitian ini adalah untuk mengetahui kelimpahan ikan karang dan jenis ikan karang yang berada di perairan Pulau Sempu.

\section{Waktu dan Tempat}

\section{MATERI DAN METODE}

Pengambilan data dilakukan pada bulan Desember 2015, di Teluk Semut, Selat Sempu, Sendang Biru, Kabupaten Malang. Pengamatan dilakukan pada waktu pagi hari di dua titik pengamatan, yaitu stasiun satu (Teluk Semut 1) dengan koordinat 112 40'52.45" BT dan $8^{\circ} 26^{\prime} 22.74$ " LS dan stasiun dua (Teluk Semut 2) dengan koordinat 112 $40^{\prime} 50.85^{\prime \prime}$ BT L $8^{\circ} 26^{\prime} 24.19^{\prime \prime}$ LS, untuk lebih jelasnya dapat dilihat pada peta Gambar (1).

\section{Pengambilan Data Ikan Karang}

Metode untuk mengkuantifikasi jumlah ikan dan ukuran ikan adalah underwater visual census yaitu mendeskripsikan ikan yang berada didalam transek $100 \times 5 \times 5 \mathrm{~m}$ (panjang, lebar dan tinggi). Pengambilan data ikan dilakukan oleh 2 orang penyelam dengan pembagian tugas tiap penyelam yaitu 2,5 meter di bagian kiri transek dan 2,5 meter di bagian kanan transek. Perhitungan dan pencatatan jumlah ikan dengan menggunakan sistem turus di sabak (underwater slate) yang sudah dibuat sebelumnya. Pengamatan dilakukan tiap 20 meter dengan jeda 5 meter sepanjang 100 meter (Gambar 2) (English et al., 1997; ReefCheck.org). 


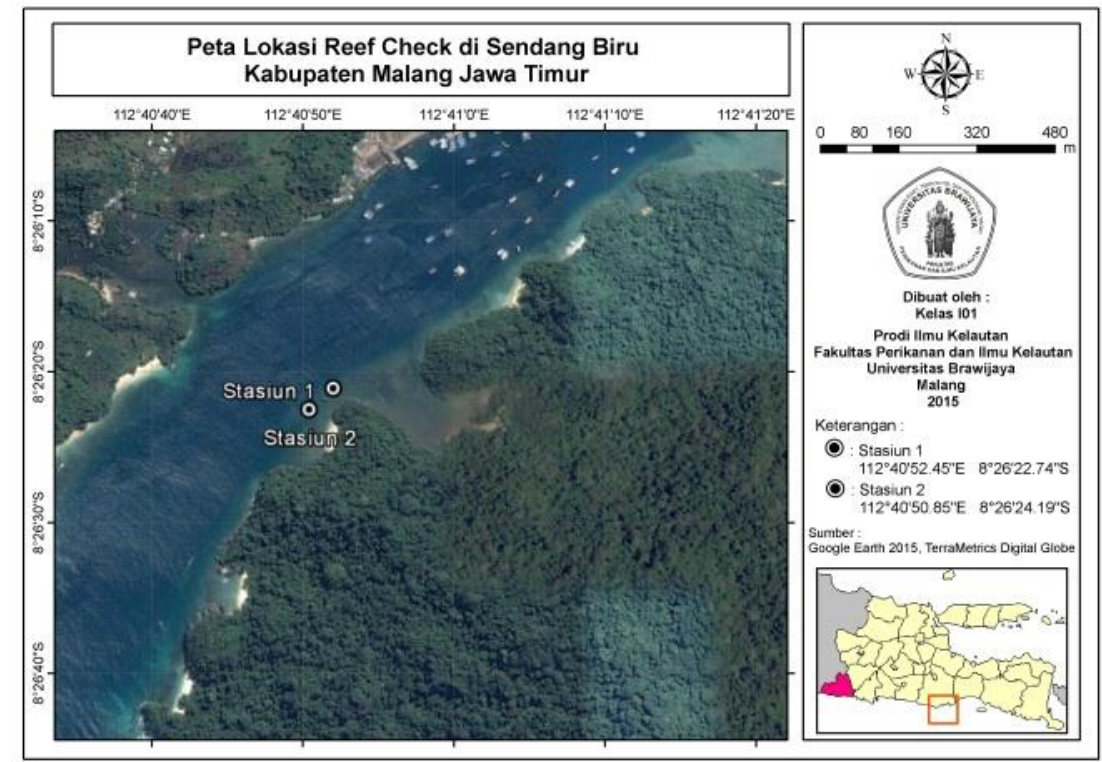

Gambar 1. Lokasi penelitian di Selat Sempu, Malang

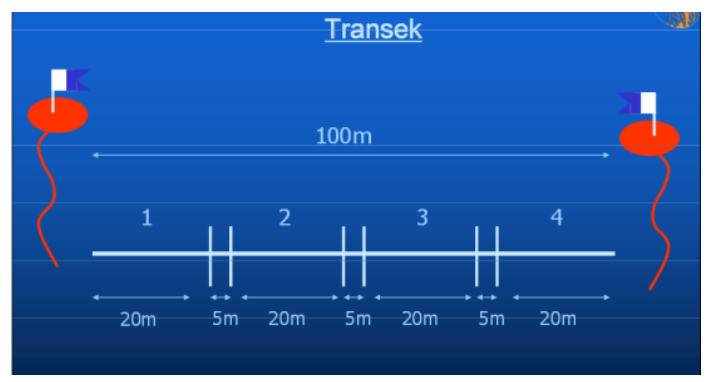

Gambar 2. Ilustrasi metode pengambilan data ikan karang menggunakan underwater visual census (UVC) (ReefCheck.org)

\section{Estimasi Ukuran Ikan Karang}

Pengukuran data ikan dapat dilakukan dengan metode estimasi ukuran ikan karang. Perbedaan dalam menentukan ukuran tidak boleh melebihi $20 \%$ dari ukuran sebenarnya ikan tersebut. Ada banyak faktor yang dapat mempengaruhi pada saat melakukan estimasi pengukuran panjang ikan yaitu objek yang terlihat lebih besar saat menggunakan masker, arah sudut ikan, tingkat kerjenihan perairan dan bentuk dari ikan yang berbeda-beda. Metode estimasi ukuran ikan karang pada penelitian ini mengacu pada metode yang diterapkan oleh reef check Indonesia, yaitu perkiraan panjang ikan menggunakan perbandingan under water slate dengan visual pengamatan secara langsung.

\section{Pengolahan Data}

Hasil pengamatan yang dilakukan akan diolah dan dianalisis dengan beberapa perhitungan untuk mengetahui kelimpahan, indeks kelimpahan dihitung menggunakan sebagai berikut:

$x=\frac{x i}{n}$

Dimana:

$$
\begin{aligned}
& \mathrm{x}=\text { kelimpahan ikan karang } \\
& \mathrm{xi}=\text { jumlah ikan pada stasiun pengamatan ke-i } \\
& \mathrm{n}=\text { luas transek pengamatan. }
\end{aligned}
$$


Indeks Keanekaragaman dihitung menggunakan indeks Shannon dan Wiener (Odum, 1983) $H^{\prime}=\sum P i \ln P i$

Dimana: $\quad H^{\prime}=$ Indeks keanekaragaman ikan karang

$\mathrm{Pi}=$ Proporsi jumlah individu (ni/ $\mathrm{N})$

Indeks Dominansi Simpson digunakan untuk menghitung dominansi spesies ikan karang

$=\sum\left(\frac{n i}{N}\right)^{2}$

Dimana: $\quad \mathrm{C}=$ Indeks Dominansi Simpson,

$\mathrm{N}=$ Jumlah individu seluruh spesies,

$\mathrm{ni}=$ Jumlah individu dari spesies ke-i.

\section{HASIL DAN PEMBAHASAN}

\section{Komposisi Ikan Karang pada Teluk Semut}

Pengamatan di Teluk Semut 1 dan Teluk Semut 2 menemukan butterflyfish pada jarak 0-20 m sebanyak 46 ekor, pada jarak 25-45 m sebanyak 56 ekor, pada jarak 50-70 m sebanyak 15 ekor dan pada jarak 75-95 sebanyak 20 ekor. Total butterflyfish yang di ditemukan adalah sebanyak 74 ekor. Jenis Haemulidae yang ditemukan pada jarak 0-20 m sebanyak 1 ekor, pada jarak 25-45 $\mathrm{m}$ adalah sebanyak 5 ekor, pada jarak 50-70 m adalah 22 ekor sedangkan pada jarak 75-95 adalah 8 ekor. Untuk jenis Snapper, pada jarak 0-20 m ditemukan sebanyak 12 ekor, pada jarak 25-45 m sebanyak 15 ekor, pada jarak 50-70m sebanyak 10 ekor dan pada jarak 75-95m sebanyak 3 ekor. Total jenis snapper yang ditemukan adalah sebanyak 40 ekor. Jenis Parrotfish ditemukan pada jarak 0-20 m sebanyak 4 ekor, pada jarak 25-45 m sebanyak 5 ekor dan pada jarak 75-95 m sebanyak 3 ekor. Untuk jenis moray eel ditemukan sebanyak 1 pada jarak 25-45 m dan ditemukan 1 pada jarak 50-70 m. Pada jarak 0-20 m dan 75-95 m tidak ditemukan jenis moray eel sehingga total yang ditemukan adalah sebanyak 2 (Tabel 1). Kelimpahan ikan terbesar adalah ikan kepe-kepe (butterflyfish) sebesar 0,34 diikuti dengan ikan kakap (snapper) sebesar 0,1 dan jenis ikan yang sangat jarang atau $<0,1$ (Tabel 2).

Tabel 1. Data ikan karang di Teluk Semut tahun 2015

\begin{tabular}{|c|c|c|c|c|c|c|c|c|c|}
\hline \multirow{3}{*}{ Jenis Ikan } & \multicolumn{8}{|c|}{ Ukuran } & \multirow{3}{*}{ Total } \\
\hline & \multicolumn{2}{|c|}{$0-20 \mathrm{~cm}$} & \multicolumn{2}{|c|}{$25-45 \mathrm{~cm}$} & \multicolumn{2}{|c|}{$50-70 \mathrm{~cm}$} & \multicolumn{2}{|c|}{$75-95 \mathrm{~cm}$} & \\
\hline & TS 1 & TS 2 & TS 1 & TS 2 & TS 1 & TS 2 & TS 1 & TS 2 & \\
\hline Butterflyfish & 25 & 21 & 30 & 26 & 12 & 3 & 7 & 13 & 137 \\
\hline Haemulidae & - & 1 & 3 & 2 & 13 & 9 & 8 & - & 36 \\
\hline Snapper (Lutjanidae) & 12 & - & 7 & 8 & 2 & 8 & 3 & - & 40 \\
\hline Barramundi cod & - & - & - & - & - & - & - & - & \\
\hline Humphead wrasse & - & - & - & - & - & - & - & - & \\
\hline Bumphead parrot & - & - & - & - & - & - & - & - & \\
\hline Parrotfish (Scaridae) & - & 4 & - & 5 & - & - & 2 & 1 & 12 \\
\hline Moray eel (Murainidae) & - & - & 1 & - & 1 & - & - & - & 2 \\
\hline Grouper & 0 & 0 & 0 & 0 & 0 & 0 & 0 & 0 & 0 \\
\hline
\end{tabular}

Ket.: TS1 = Teluk Semut 1; TS2 = Teluk Semut 2 
Tabel 2. Kelimpahan ikan karang per $\mathrm{m}^{2}$ di Teluk Semut tahun 2015

\begin{tabular}{|c|c|c|c|c|c|c|c|c|c|}
\hline \multirow{3}{*}{ Jenis Ikan } & \multicolumn{8}{|c|}{ Ukuran } & \multirow{3}{*}{ Total } \\
\hline & \multicolumn{2}{|c|}{$0-20 \mathrm{~cm}$} & \multicolumn{2}{|c|}{$25-45 \mathrm{~cm}$} & \multicolumn{2}{|c|}{$50-70 \mathrm{~cm}$} & \multicolumn{2}{|c|}{$75-95 \mathrm{~cm}$} & \\
\hline & TS 1 & TS 2 & TS 1 & TS 2 & TS 1 & TS 2 & TS 1 & TS 2 & \\
\hline Butterflyfish & 0.25 & 0.21 & 0.3 & 0.26 & 0.12 & 0.03 & 0.07 & 0.13 & 0.3425 \\
\hline Haemulidae & - & 0.01 & 0.03 & 0.02 & 0.13 & 0.09 & 0.08 & - & 0.09 \\
\hline Snapper (Lutjanidae) & 0.12 & & 0.07 & 0.08 & 0.02 & 0.08 & 0.03 & - & 0.1 \\
\hline Parrotfish (Scaridae) & - & 0.04 & - & 0.05 & - & - & 0.02 & 0.01 & 0.03 \\
\hline Moray eel (Murainidae) & - & - & 0.01 & - & 0.01 & - & - & - & 0.005 \\
\hline
\end{tabular}

Hasil identifikasi ikan karang yang paling banyak adalah butterflyfish sebanyak 74 ekor, kemudian jenis Haemulidae sebanyak 24 ekor, selanjutnya adalah jenis snapper sebanyak 24 ekor, parrotfish sebanyak 2 ekor dan yang terakhir adalah jenis moray eel sebanyak 2 ekor (Gambar 3). Indeks Keanekaragaman ( $\mathrm{H}^{\prime}$ ) ikan karang di Teluk Semut 1 dan Teluk Semut 2 yaitu sebesar 0.22 . Berdasarkan analisis Indeks Keanekaragaman, nilai yang didapat termasuk dalam kategori rendah atau kecil. Hal ini dikarenakan variasi jenis ikan karang yang sedikit. Hasil perhitungan Indeks Dominansi (C) di Teluk Semut 1 dan Teluk Semut 2 yaitu sebesar 0.084 . Indeks Dominansi termasuk dalam kategori rendah atau kecil. Hal ini dikarenakan di lokasi Teluk Semut 1 dan Teluk Semut 2 tidak di dominasi oleh spesies tertentu.

Menurut Low dan Chou (1994), ikan karang dapat juga dikelompokkan dalam 3 kelompok yakni: ikan indikator dari family Chaetodontidae, ikan target (ekonomis penting) dimana jenis ikan yang ditangkap untuk tujuan konsumsi seperti dari famili Seranidae, Lutjanidae, Kyphosidae, Lethrinidae, Acanthuridae, Mulidae, Siganidae, dan Haemulidae. Selanjutnya ikan mayor terdiri atas Pomacentridae (ikan betok laut), Labridae, Pomacanthidae, Caesionidae dan Carangidae.

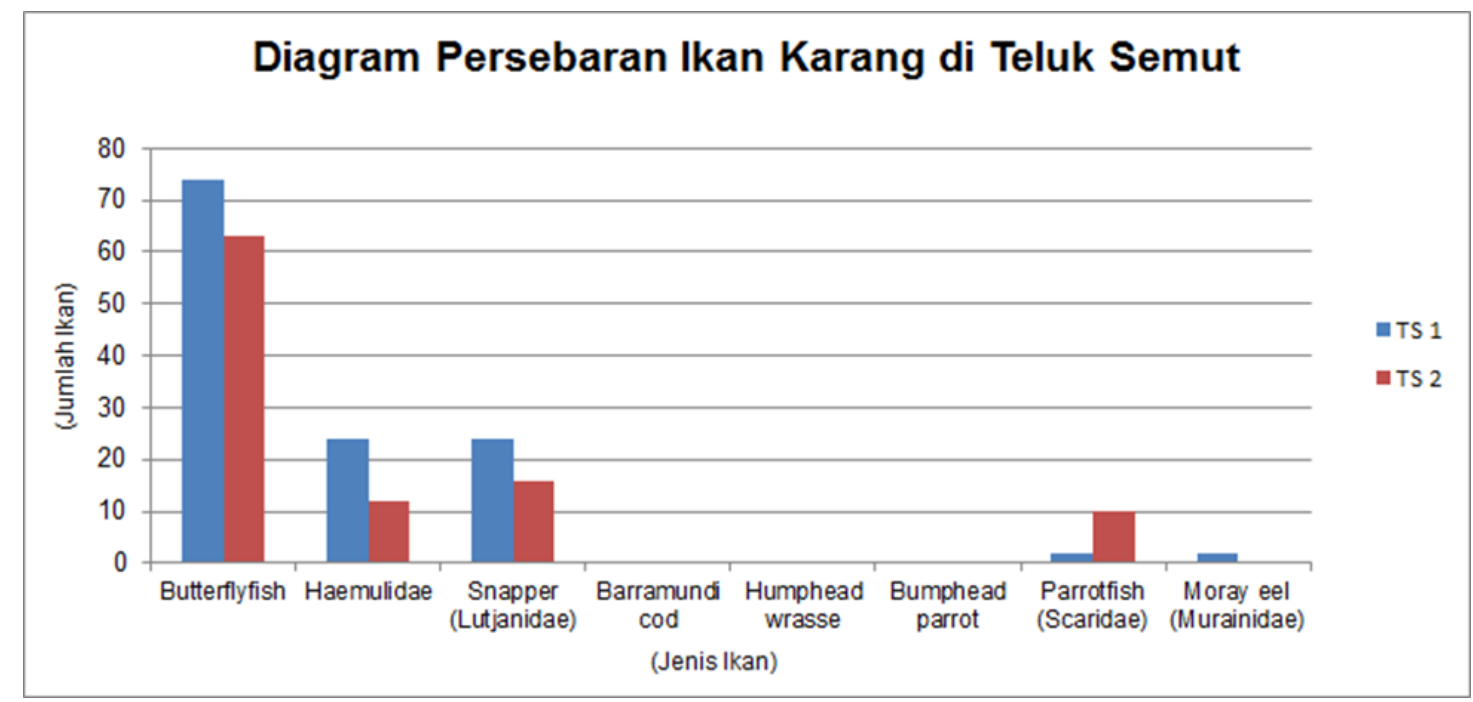

Ket. TS 1: Teluk Semut 1; TS 2: Teluk Semut 2

Gambar 3. Sebaran ikan di Selat Sempu, Malang

Hasil pengamatan menunjukkan ikan karang yang paling banyak ditemui adalah ikan famili Chaetodontidae. Ikan ini sebagai indikator kondisi terumbu karang suatu perairan. Apabila jumlah ikan jenis ini yang melimpah dapat diartikan bahwa kondisi terumbu karang masih baik. Rendahnya jumlah ikan ini di perairan Selat Sempu menunjukan kondisi terumbu karang di 
perairan ini tidak baik atau telah rusak. Kerusakan terumbu karang dapat disebabkan oleh aktifitas penangkapan yang tinggi di daerah ini. Penyebab lainnya adalah limbah dari aktifitas manusia yang bermukim di dekat perairan. Limbah ini membuat kondisi perairan tercemar dan mengganggu kondisi terumbu karang. Butterflyfish merupakan ikan omnivore atau pemakan segala, dan beberapa spesies dari jenis ini sangat tergantung pada karang yang merupakan habitat hidup dan makanan utamanya (Pereira and Videira, 2007).

Kelimpahan ikan Chaetodontidae mencerminkan kondisi suatu terumbu karang, jumlah tutupan karang hidup yang tinggi berkorelasi positip dengan jumlah ikan yang ada dalam ekosistem tersebut. Chaetodon unimaculatus banyak memakan polip dari karang berbentuk daun montiporid (Acroporidae) sedangkan Chaetodon ornatissimus dan Chaetodon multicinctus memiliki kesukaan pada jenis karang Porites (Belland Galzin, 1984; Cox, 1994).

Famili dengan jumlah terbanyak kedua adalah Haemulidae dan Lutjanidae. Ikan karang ini tergolong sebagai ikan target atau ikan konsumsi atau ikan dengan nilai ekonomis. Ikan karang ini yang menjadi target penangkapan oleh nelayan. Semakin banyak ikan jenis ini maka semakin banyak pula hasil tangkapan nelayan dan semakin tinggi pula keuntungan yang diperoleh nelayan. Kondisi ini dapat meningkatkan kesejahteraan nelayan di perairan tersebut. Keberadaan ikan jenis tersebut di perairan Selat Sempu menunjukan perairan ini memiliki potensi perikanan yang baik apabila kondisi perairan terus dijaga dan dirawat, sehingga keberadaan ikan-ikan target semakin melimpah. Ukuran ikan target di wilayah ini didominasi dengan ukuran ikan yang $<50 \mathrm{~cm}$ yang menjadi indicator bahwa adanya efek penangkapan ikan berlebih selama bertahun-tahun. Berkurangnya ikan ekonomis penting yang merupakan predator bagi ikan lain akan meningkatkan jumlah ikan atau invertebrate tertentu yang akan mengganggu ekosistem terumbu karang (Gislason, 2003).

Hasil pengamatan ikan lainnya adalah jenis Scaridae dan Murainidae. Jumlah jenis tersebut lebih sedikit dibandingkan yang lainnya. Jenis scaridae atau jenis pomacentridae yang berperan sebagai ikan herbivore jarang ditemui dan jumlah individu yang sangat sedikit. Ikan herbivore memiliki peran yang penting di ekosistem terumbu karang. Keberadaan ikan ini akan mengontrol pertumbuhan alga di terumbu karang. Hal ini menjadi penting karena keberadaan alga dapat merugikan bagi karang. Substrat yang ditumbuhi alga akan menghambat dan mengurangi keberhasilan rekruitmen karang (Arnold et al., 2010). Apabila rekruitmen karang rendah maka pertumbuhan karang baru akan rendah sehingga penambahan penutupan karang akan turut rendah atau tidak berubah.

\section{KESIMPULAN DAN SARAN}

Kesimpulan yang dapat ditarik adalah :

1) Keberadaan dan kelimpahan ikan jenis Chaetodontidae yang rendah, sebagai ikan indikator kondisi terumbu karang menunjukkan bahwa kondisi terumbu karang di Selat Sempu telah rusak atau kurang baik.

2) Perairan Selat Sempu memiliki potensi perikanan apabila kondisi terumbu karang tetap dijaga dan terus dirawat karena menjadi habitat bagi ikan - ikan target perikanan seperti famili Haemulidae dan Snapper yang memiliki nilai ekonomis.

3) Keberadaan ikan herbivore seperti famili Scaridae dan Pomacentridae yang sedikit membuat pertumbuhan alga di perairan dapat tidak terkendali dan dapat menghambat rekruitmen karang baru.

Ekosistem terumbu karang yang meliputi karang, ikan dan invertebrate di kawasan cagar alam Pulau Sempu yang berdekatan dengan daerah pemanfaatan (PPN Sendang Biru) adalah termasuk kawasan yang berkategori sangat rentan, dikarenakan aktivitas perikanan yang cukup aktif. Untuk itu perlu kegiatan monitoring secara berkala agar bisa dilihat laju perubahan ekosistem terumbu karang (termasuk ikan karang) didalamnya. 


\section{UCAPAN TERIMA KASIH}

Terima kasih kami ucapkan kepada mahasiswa selam keahlian untuk membantu pengambilan data di lapangan. Terima kasih juga kami sampaikan kepada semua pihak yang telah banyak berdiskusi mengenai tulisan ini.

\section{DAFTAR PUSTAKA}

Arnold, S. N., Steneck, R., and Mumby, P. J. (2010). Running the gauntlet: inhibitory effects of algal turfs on the processes of coral recruitment. Marine Ecology-Progress Series, 414, 91.

Bell, J. D., \& Galzin, R. (1984). Influence of live coral cover on coral-reef fish communities. Marine Ecology Progress Series, 15(3), 265-274.

Cole, A. J., Pratchett, M. S., and Jones, G. P. (2009). Effects of coral bleaching on the feeding response of two species of coral-feeding fish. Journal of Experimental Marine Biology and Ecology, 373(1), 11-15.

Cox, E. F. (1994). Resource use by corallivorous butterflyfishes (Family Chaetodontidae) in Hawaii. Bulletin of Marine Science, 54(2), 535-545.

Dearden, P., Theberge, M., \& Yasue, M. (2010). Using underwater cameras to asses the effects of snorkeler and scubs diver presence on coral reef fish abundance, family richness, and species composition. Journal of Environt. Monnit. Asses., 163: 531-538.

English, S., Wilkinson, C., \& Baker, V. (1997). Survey manual for tropical marine resources, 2nd edn. Australian Institute of Marine Science, Townsville

Gislason, H. (2003). The Effects of Fishing on Non-target Species and Ecosystem Structure and Function. Responsible fisheries in the marine ecosystem, 255.

Halford, A. R., \& Thompson, A. A. 1994. Visual census surveys of reef fish standart operational procedure number 3. Australian Institue Of Marine Science. Townsville

http://www.reefcheck.org/.

Jackson, J. B., Kirby, M. X., Berger, W. H., Bjorndal, K. A., Botsford, L. W., Bourque, B. J., \& Hughes, T. P. (2001). Historical overfishing and the recent collapse of coastal ecosystems. science, 293(5530), 629-637.

Joyce, K. E, Phin, S. R., Roelfsema, C. M., Neil, D. T., \& Dennison, W. C. (2004). Combining Landsat ETM+ and reef check classification for mapping coral reff : a critical assesment from The Southern Great Barrier Reef, Australia. Journal of Coral Reef, 23, 21-25. Springer

Low, J. K., \& Chou, L. M. (1994). Sedimentation rates in Singapore waters. In Proc 3rd ASEANAust Symp Living Coral Resources (Vol. 2, pp. 697-701).

Odum, E. P. (1983). Basic ecology. Saunders College Publishing, New York. 612 pp.

Pereira, M. A., \& Videira, E. J. (2007). Distribution and community structure of butterflyfishes (Pisces: Chaetodontidae) in Southern Mozambique. Western Indian Ocean Journal of Marine Science, 4(1), 39-46.

Pet-Soede, C., Cesar, H. S. J., \& Pet, J. S. (1999). An economic analysis of blast fishing on Indonesian coral reefs. Environmental Conservation, 26(2), 83-93.

Wilkinson, C. R. (1999). Global and local threats to coral reef functioning and existence: review and predictions. Marine and Freshwater Research, 50 (8), 867-878. 